\title{
Quando jogar é aprender: o videogame na sala de aula
}

When playing is learning: video games in the classroom

\author{
Vilson J. Leffa \\ Universidade Católica de Pelotas \\ CNPq \\ Hilário I. Bohn \\ Universidade Católica de Pelotas \\ Vanessa D. Damasceno \\ Universidade Federal do Pampa \\ Gabriela Q. Marzari \\ Centro Universitário Franciscano
}

Resumo

Este trabalho tem por objetivo demonstrar a tese de que o videogame pode se constituir em um importante instrumento de mediação na aprendizagem de línguas. Para isso, destaca três aspectos do videogame: (1) o videogame é uma prática social caracterizada pelo uso intensivo da língua; (2) o videogame envolve o jogador por imersão, trazendo-o para dentro do jogo; e (3) o videogame, ao mesmo tempo em que exige o conhecimento da língua para ser jogado, propicia sua aprendizagem. A conclusão é de que o videogame, visto como um objeto de lazer, pode resultar na aprendizagem da língua, oferecendo ao aluno três opçôes: (1) aprender a língua para jogar; (2) jogar para aprender a língua; e (3) fazer as duas coisas ao mesmo tempo.

Palavras-Chave

Videogames, Aprendizagem de línguas, Letramento digital, Prática social. 


\section{Abstract}

This paper aims to demonstrate the thesis that a video game may be an important mediational instrument in language learning. For this purpose, three aspects of video games are highlighted: (1) a video game is a social practice characterized by intensive language use, (2) a video game brings the player into the game, involving immersion, (3) a video game, while requiring language competence to be played, also affords language learning. The conclusion is that a video game, seen as an object of leisure, can result in learning the language, giving the student three options: (1) learning the language to play, (2) playing to learn the language, or (3) doing both things at the same time.

\section{Keywords}

Videogames, Language learning, Digital literacy, Social practice. 


\section{Introdução}

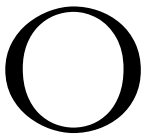

videogame pode ser visto, ao mesmo tempo, como um jogo de fantasia e realidade. Como fantasia, representa a fuga momentânea do jogador para um mundo virtual, propiciado pela interação com a máquina; terminada a sessão, o mundo real retoma seu domínio e o jogo fica apenas na lembrança, como atividade inofensiva de lazer, sem consequências para o jogador, que pode ter destruído cidades, decapitado soldados, raptado princesas, mas sabe muito bem que o virtual não se confunde com o real e retoma as tarefas do cotidiano, sem trauma. Já quando o videogame é visto como realidade, há um vazamento do virtual sobre o real. O jogador, depois do jogo, não é a mesma pessoa de antes. $O$ contato com o imaginário sobrenatural, típico dos videogames, como a deformação virtual do corpo em demônios e monstros, além da exacerbação da violência, muitas vezes gratuita, pode trazer consequências para o jogador, produzindo deformaçōes reais. $\mathrm{O}$ que deveria ser apenas uma atividade inofensiva de lazer transforma-se num vício perigoso, uma fuga permanente da realidade, produzindo um sujeito antissocial, capaz até de cometer assassinatos (CORACINI, 2006).

Este trabalho parte do pressuposto de que o videogame não é uma fantasia anódina, uma atividade meramente virtual que se desmancha no ar no momento em que o jogador desliga a máquina. Acredita-se que uma sessão de videogame produz um impacto permanente no indivíduo, de modo mais intenso do que um livro, uma música ou um filme, visto que há um envolvimento físico maior do sujeito. Para ler um livro ou ouvir uma música, usamos normalmente apenas um dos nossos sentidos, visão ou audição; para um filme, usamos os dois, mas, para um videogame, entramos com os olhos, ouvidos e gestos, tocando um painel ou mesmo movimentando o corpo na frente de uma câmera, acoplada ao sistema. Se um livro, dependendo de seu conteúdo, pode transformar um leitor em assassino ou santo, parece óbvio supor que o mesmo pode acontecer com o videogame, provavelmente até com intensidade maior, pelo fato de o usuário 
entrar de corpo inteiro. Um livro modifica a mente do leitor, o videogame muda a mente e o corpo. O uso de videogames para tratamentos fisioterápicos (RODRIGUES, 2009) pode ser citado como um exemplo desse impacto no próprio corpo, uma vez que possibilita programas de reabilitação, "por exigir que os jogadores executem movimentos que ajudam a reconquistar o equilíbrio, coordenação, resistência e força muscular" (CYRILLO, 2011).

A sedução do videogame pode ser vista tanto como uma ameaça como um benefício, embora o destaque tenha sido dado para os aspectos negativos, considerando o que é veiculado pela mídia e o que dizem os professores. A mídia, com base no consenso de que a tragédia tem um apelo maior para o público e vende mais, tem destacado, de modo desproporcional, o lado negativo, divulgando histórias de crianças viciadas que deixam de se alimentar para não sair da frente do videogame que acabam se transformando em psicopatas. Já os professores, na melhor das hipóteses, veem o videogame como um letramento marginal (KNOBEL; LANKSHEAR, 2007, p. 13), quando não conflituoso com os interesses da educação (NOVA ESCOLA, 2009). O videogame parece reverter a expectativa do professor, que, no contexto da escola, sempre se identificou como condutor do aluno, ensinando-o a ler e escrever, por saber mais do que ele; no caso do videogame, acontece o contrário: é o aluno que sabe mais e, se a tecnologia fosse adotada pela escola, teria de ser levada por ele, não pelo professor, que tipicamente ainda não adquiriu o letramento digital que o aluno já possui. É uma situação estranha e inaceitável para o conceito que normalmente se tem de escola, e provavelmente mais um aspecto que contribui para a rejeição do videogame, revertendo em prejuízo do aluno, que não pode capitalizar em cima do que já sabe (SNYDER, 2009).

O objetivo deste trabalho é investigar a potencialidade didática do videogame, com ênfase no ensino de línguas. Para mostrar seu possível impacto na aprendizagem, sentimos a necessidade de fazer inicialmente um levantamento das diferentes categorias de games, demonstrando como sua evolução e crescente complexidade levam à constatação de que o videogame é uma prática social, desde o jogo coletivo presencial até os jogos em rede, incluindo os RPGs (Role Playing Games) e os RTS (Real Time Strategy), com seus avatares e a possibilidade de construção de diferentes identidades. Na segunda parte, tenta-se definir o que é um videogame, partindo de suas características e propondo-se uma definição com base na Teoria dos Protótipos. Na terceira parte, 
pretende-se mostrar um possível caminho para a introdução do videogame na educação, com destaque para a aprendizagem de línguas e com base nos princípios dos games e seus possíveis impactos na aprendizagem, conforme proposta de Gee (2003), chegando à ideia do "aprender a ser". Entende-se que a transposição do videogame do ambiente doméstico e dos fliperamas para a sala de aula implica um processo mais ou menos longo de aceitação, que inicia com uma etapa de rejeição, passa pela inserção e finalmente pode chegar à naturalização, seguindo o caminho histórico da invisibilização, que caracteriza a evolução das tecnologias (CHAMBERS; BAX, 2006; PAIVA, 2008; LEFFA, 2009).

A tentativa de mostrar a evolução do videogame, enquadrá-lo em uma definição e mostrar seu possível impacto na sala de aula revelou-se bem mais complexa do que esperávamos. Existe tal afluência de ideias e propostas na área dos games que só para resumi-las seria necessário um livro inteiro. Como não queríamos apenas apresentar uma lista de autores e obras, optamos por escolher, da vasta literatura já existente sobre o tema, aquilo que entendemos como essencial, tomando, no entanto, o cuidado de produzir um texto autossuficiente, aprofundando os tópicos selecionados, de modo que o leitor não precise consultar outras obras para compreender a tese que defendemos neste texto. Para aqueles, no entanto, que desejarem ampliar seus conhecimentos, já deixamos o caminho aberto, referenciando com cuidado as obras mais relevantes do tema abordado, incluindo, quando disponível, o endereço de acesso na internet.

\section{Evolução do videogame}

Vamos tentar resumir nesta seção a evolução do videogame, que pode ser descrita em três grandes momentos: (1) a fase do jogo presencial coletivo, que caracteriza os primórdios do videogame, (2) a fase doméstica, em que o jogo se torna uma atividade privada e (3) a fase do jogo em rede, que se caracteriza pela fusão do real com o virtual, provocando a multiplicação da subjetividade em inúmeras identidades, quer se corporificando em diferentes avatares, quer interagindo com outras subjetividades. Cada uma dessas fases indica o predomínio de um determinado tipo de jogo, sem necessariamente excluir os outros, havendo até uma interpenetração que tende a crescer com o passar do tempo. 
Embora não haja consenso sobre a origem exata do videogame, tem-se sugerido como a data mais indicada de seu nascimento o dia 8 de outubro de 1958. Nesse dia, na feira anual do Brookhaven National Laboratory, em Nova York, foi apresentado ao público o jogo eletrônico "Tennis for Two", criado pelo físico nuclear William Higinbotham, com o objetivo de "animar a feira com um jogo em que as pessoas pudessem interagir, e que transmitisse a mensagem de que nossos empreendimentos científicos têm relevância para a sociedade" (HIGINBOTHAM, 1983, p.2). O jogo foi um sucesso; centenas de pessoas formavam fila nos corredores da feira, esperando a oportunidade de jogar o tênis eletrônico, o que era feito em duplas, por meio de controles manuais, na frente de uma telinha redonda de cinco polegadas. A bola era um ponto luminoso, que deixava uma cauda de luz quando se movimentava na tela, como se fosse um pequeno cometa; a quadra e a rede eram duas linhas de cor verde (GETTLER, 2008).

Três aspectos devem ser destacados nesse evento, pela sua importância na tese que se pretende desenvolver neste ensaio sobre a relevância do jogo na aprendizagem. O primeiro é o lugar de nascimento do videogame: um laboratório de pesquisa que recebeu, ao longo de sua história, sete prêmios Nobel por suas investigações, envolvendo pesquisadores permanentes e visitantes. $\mathrm{O}$ segundo aspecto é a possibilidade de relevância social do videogame, originalmente apresentado ao público em uma feira, um evento essencialmente grupal, caracterizando-se, portanto, mais como um ritual coletivo do que uma atividade individual ou privada. O terceiro é a preocupação de Higinbotham com a interação, desde o título dado ao game - Tennis for Two (Tênis para Dois), possibilitando que duas pessoas jogassem ao mesmo tempo - até a tentativa de atrair o público para a feira, oferecendo algo mais dinâmico do que pôsteres e equipamentos estáticos (GETTLER, 2008).

Até a década de 1970, os videogames, pelo seu alto custo, só podiam ser jogados em universidades e espaços públicos (VIDAL, 2011); o computador PDP-1, necessário para rodar o game Spacewar, por exemplo, custava, no início da década de 1960, 120 mil dólares, em valor não atualizado. A popularização dos videogames surgiu com a substituição dos computadores por fliperamas, que eram máquinas construídas especificamente para mostrar videogames, cada uma dedicada a um determinado jogo. Essas máquinas eram usadas pelo público em locais de livre acesso, sem restrições de idade ou sexo. Jogar um videogame era 
um evento social de natureza familiar, às vezes, com homens e mulheres elegantemente vestidos. Conforme depoimento de um usuário da época:

Os garotos levavam suas garotas, os pais levavam seus filhos, os homens iam com seus colegas de trabalho após o expediente e tudo isso atraídos por jogos clássicos como Pacman, Battlezone, Zaxxon e Space Invaders. (JBRUNO, 2011).

Foi só com a introdução dos consoles, aparelhos que funcionavam conectados a um televisor, que o videogame chegou aos lares. Em 1972, surgiu a Atari, que introduziu a indústria dos games e tornou-se a empresa mais importante do setor nas décadas de 1970 e 1980, trazendo o videogame para a vida privada e aparentemente provocando a decadência social dos fliperamas. Conforme depoimento de um usuário dessa época de declínio, percebe-se uma relação implícita entre "o conforto de jogar em casa", que não havia antes, e a criminalização dos fliperamas, que começa a ocorrer:

Não sinto saudade dos fliperamas...

- Antro de maus elementos, drogas e delitos.

- Caros pra jogar (...).

- Não tem o conforto de jogar em casa. (MANJASTER, 2008).

Esta fase de privatização do videogame coincide mais tarde com o acesso à internet, antes restrito às universidades e depois privatizado para acesso doméstico a quem possuísse o equipamento adequado, ou a empresas que às vezes disponibilizavam esses equipamentos para quem não os possuísse, em lugares de acesso público, conhecidos como lan houses. Uma comparação entre os países mais ricos e mais pobres mostra que a lan house é uma instituição típica dos países mais pobres, sustentada por pessoas que não possuem recursos para adquirir equipamentos de informática e que resistem a ser digitalmente excluídas. A criminalização das lan houses, como já tinha acontecido com os fliperamas, foi imediata e não faltaram tentativas de restringir seu acesso por meio de decretos e normas em diferentes esferas de poder, tanto locais, incluindo escolas e universidades, como nas instâncias municipais, estaduais e federais, gerando debates acalorados entre os que condenam as lan houses como antros de perdição e os que as defendem. O depoimento do presidente da ONG Laboratório 
Brasileiro de Cultura Digital, na Câmara dos Deputados sobre um projeto de lei impondo restrições às lan houses é emblemático desse embate:

As lan houses não são um antro de perdição, mas um antro de esperança. São os campinhos de várzea da cultura digital (PRADO, 2011).

$\mathrm{Na}$ terceira fase, entramos nos jogos em rede. Entre as diferentes modalidades, os mais populares são os MMOGs (Massive Multiplayer Online Games), que se caracterizam por serem jogados por um grande número de pessoas, que interagem não só com sujeitos do mundo real, tipicamente representados por avatares, mas também com personagens do mundo virtual. Essa fusão da virtualidade com a realidade parece surgir de dois modos, tanto pela descoberta como pela invenção. Temos uma descoberta quando o mundo tido como irreal, representado na virtualidade, é percebido como um espelho do mundo real. Nesse caso, o que vemos como irreal é igual ao que vemos como real, como se fosse uma duplicação. Cada detalhe da roupa que o soldado veste, da arma que ele carrega, do tanque de guerra que ele manobra, cada gesto possível é uma réplica perfeita do que acontece, ou pode acontecer, numa batalha real. Por outro lado, temos uma invenção quando o irreal é visto como irreal mesmo, diferente do mundo físico que habitamos. A invenção deixa de ser uma cópia fiel para se transformar numa projeção da realidade, ampliando os detalhes, aumentando a força, intensificando as emoções. Os soldados frágeis transformam-se em gigantes musculosos, adolescentes tímidos em super-heróis, cheios de mistérios e poderes. É o mundo da fantasia, que prima pelos extremos, da agonia ao êxtase, quer habitado por monstros, magos ou feiticeiros, quer habitado por fadas, príncipes ou princesas. Mesmo assim, em que pese essa aparente ruptura entre descoberta e invenção, há uma continuidade entre elas, na medida que tranquilamente transitamos de um mundo para outro, da descoberta para a invenção, da fantasia para a realidade e vice-versa. Vejamos alguns exemplos, no mundo dos jogos.

Uma continuidade que se percebe de imediato é que participar de um MMOG é como participar de um clube em que se paga uma mensalidade para jogar com outras pessoas; o MMOG pode ser virtual, mas a mensalidade é real e vai ser debitada no cartão de crédito. Já uma diferença é que o clube virtual não tem um endereço fixo, mas forma uma rede ao redor do planeta, criando um nó 
de acesso no endereço de cada jogador, chegando, em alguns casos, a milhões de nós. World of Warcrat (WOW) tinha em 2011 mais de 11 milhões de assinantes (VENTICINQUE, 2011), um número que é 282 vezes maior do que os $39 \mathrm{mil}$ sócios informados pelo Sport Club Corinthians de São Paulo (http:// www.corinthians.com.br/). Além dessa diferença quantitativa, há outras, de natureza mais qualitativa, da própria essência do que percebemos como virtual e real. No mundo real, o jogador vai até o clube; no mundo virtual é o clube que vem até ele. No clube virtual, todos os 11 milhões de sócios são jogadores; no clube real, a grande maioria é formada por expectadores.

Olhando da perspectiva da aprendizagem, vista como aquisição de uma nova identidade, o MMOG apresenta duas características que merecem ser destacadas, pelo impacto que pode trazer para a aprendizagem: (1) a definição do avatar e (2) a necessidade de colaboração para cumprir determinadas missóes. Usando como exemplo o $W O W$, quando o jogador entra para o clube, a primeira coisa que ele deve fazer é definir seu avatar, ou seja, escolher em que personagem deseja se transfigurar. No caso do $W O W$, a opção se inicia por uma das doze raças a que deseja pertencer, cada uma com sua língua, sua pátria e seus traços físicos e psicológicos. Definida a raça, escolhe-se uma das dez classes disponíveis atualmente (guerreiro, caçador, sacerdote, mago, paladino, etc.), cada uma com diferentes níveis de poder e habilidade para executar determinadas tarefas.

Um avatar tipicamente tem poderes que as pessoas não possuem na vida real, sendo, portanto, capaz de potencializar o sujeito e tornar muitos de seus desejos em realidade. Essa potencialização já estava presente nas máscaras do teatro grego que ampliavam a voz dos autores, nas armaduras dos guerreiros e continua presente nas obras de ficção contemporâneas. No filme Avatar, o herói paraplégico transfigura-se num guerreiro poderoso quando assume seu avatar. Às vezes, o poder surge na simples transfiguração, independentemente da aparência, poderosa ou singela, do avatar; no filme The Beaver, Mel Gibson transforma-se completamente, assumindo a identidade de um executivo e chefe de família bem-sucedido quando fala pela voz da marionete. Estudos na área da Psicanálise têm demonstrado o efeito benéfico de marionetes no tratamento de alguns distúrbios mentais (VAISBERG, 2002). Efeitos semelhantes também foram encontrados no ensino de línguas, principalmente no desenvolvimento da fala com alunos tímidos (ASHER, 2010): crianças extremamente introvertidas que se negam a conversar, tornam-se falantes fluentes quando se projetam em marionetes. 
Um MMOG é também uma sociedade complexa com suas normas e divisão de trabalho, em que o cumprimento de muitas missões só é possível pela colaboração entre seus membros. Há muitas tarefas que precisam ser executadas em grupo e o jogador deve fazer parte de determinadas associaçōes (guilds); a missão fica comprometida se não houver no grupo alguém com os poderes necessários para resolver algum problema inesperado que possa surgir. Um guerreiro, por exemplo, pode precisar de um sacerdote, que tem poderes de cura, para que seus ferimentos sejam tratados. A ideia de cooperação extrapola o próprio jogo, chegando aos inúmeros fóruns, blogs e comunidades que são criados para ajudar os iniciantes, esclarecer dúvidas ou programar eventos de interesse dos jogadores.

A evolução do videogame parece apontar para várias direçōes, produzindo diferentes deslocamentos. De uma experiência inicial como evento coletivo, geograficamente restrito, evolui para uma atividade privada, de caráter mais individual, mas acaba retomando sua natureza coletiva, ampliando-se para as redes sociais da internet. Essa evolução, como vimos, caminha em dois sentidos: o da descoberta e o da invenção. No primeiro caso, tenta descobrir diferentes segmentos da realidade, mostrando, entre outros aspectos, o realismo das guerras e dos grandes eventos esportivos, trazendo para a virtualidade toda a riqueza de detalhes do mundo real, de modo a se confundir com ele. No segundo caso, o videogame, além da descoberta do mundo real, busca inventar um mundo fantástico, com base numa espécie de realismo mágico, igualmente rico em detalhes. Se no primeiro caso há um transbordamento da realidade para a virtualidade, no segundo caso ocorre o contrário: é o jogo que impacta os jogadores. $\mathrm{O}$ resultado é a fusão entre a virtualidade e a realidade.

\section{O que é um videogame}

$O$ videogame é um gênero do discurso multimodal que se define pela presença de determinadas características como ludicidade, interatividade, imprevisibilidade, suporte eletrônico, ação física do jogador, entre outras. A maioria dessas características são variáveis contínuas: um videogame pode ter um grau maior ou menor de ludicidade, pode ser mais ou menos interativo, mais ou menos imprevisível, etc. Contudo, ao lado das variáveis contínuas, o videogame possui também variáveis categóricas, que não são medidas por uma 
escala de valor, mas por pertencer, ou não, a uma determinada categoria. A variável suporte, por exemplo, é categórica: para o videogame, o suporte será tipicamente um circuito eletrônico capaz de executar instruçôes, ao contrário de muitos outros jogos que têm como suporte elementos estáticos como o papel ou o tabuleiro. Um videogame pode criar suas próprias variáveis categóricas, como impérios, raças, línguas, armas, etc.

As variáveis, tanto as contínuas como as categóricas, podem também ser obrigatórias ou opcionais. O valor educativo de um videogame é uma variável opcional, já que este valor pode ou não estar presente no jogo, ao contrário do valor de entretenimento, que é uma variável de presença obrigatória. Entre as variáveis categóricas, o suporte eletrônico é normalmente considerado uma variável obrigatória do videogame, ao contrário, por exemplo, de uma variável categórica como "versão em língua portuguesa", que é opcional.

Vemos, então, que há variáveis obrigatórias e opcionais, que podem ser categóricas e contínuas, e que, quando contínuas, podem se apresentar com maior ou menor intensidade. A combinação de todos esses elementos, em diferentes doses, pode produzir uma grande variedade de videogames e levar eventualmente à produção do que poderia ser considerado o videogame prototípico, como aquele que reunisse os traços mais frequentes de todos os videogames. É o que se entende como prototipicidade. $\mathrm{O}$ valor de entretenimento de um jogo, por exemplo, é mais importante para defini-lo como videogame do que seu valor educativo. O bom videogame é aquele que vicia, não necessariamente aquele que ensina; um jogo pedagógico com ênfase no uso de recursos interativos, mas com baixo valor de entretenimento, ficaria na fronteira entre o videogame e o exercício didático.

Vejamos algumas dessas variáveis, categóricas e contínuas, que caracterizam o videogame. Entre as categóricas, destacamos: (1) o algoritmo, (2) a ação física do jogador e (3) o suporte eletrônico. Consideramos como contínuas: (1) a ludicidade, (2) a interatividade e (3) a explicitação de valores.

\subsection{O algoritmo}

$\mathrm{O}$ videogame tem um algoritmo. $\mathrm{O}$ algoritmo é uma sequência de instruções em linguagem de máquina que usa o circuito interno de um dispositivo eletrônico, computador ou console, para se instanciar, produzindo um evento lúdico, que é, ao mesmo tempo, recorrente e único. É recorrente porque 
há elementos que se repetem entre uma instanciação e outra; é único porque os elementos se repetem em cada evento de maneira imprevisível. Dois recursos importantes de um algoritmo computacional são (1) a capacidade de analisar dados para tomar decisóes e (2) a produção de ações aleatórias. A tomada de decisôes acontece nos "pontos de viragem", aqueles locais de ramificação no algoritmo em que o sistema opta por uma ou outra direção, dependendo do que já aconteceu anteriormente, com base no teste do "se... então": "se o usuário conseguiu tantos pontos, passar para a etapa seguinte", entre tantas outras possibilidades. Já a produção de ações aleatórias tem por base a capacidade dos sistemas computacionais de gerar sementes randômicas, produzindo ações de natureza imprevisível: não é possível saber, por exemplo, de onde surgirá o adversário, o que ele fará num determinado momento ou que resposta dará a uma intervenção do usuário. $\mathrm{O}$ algoritmo faz do videogame um evento interativo, sensível aos gestos do usuário, às vezes respondendo ao que ele faz, às vezes propondo ações novas.

\subsection{Ação física do jogador}

$\mathrm{O}$ jogador de um videogame age sobre o jogo. O leitor de um livro ou o espectador de um filme processa a informação de modo receptivo, o leitor usando os olhos e o espectador, acrescentando aos olhos os ouvidos, já que não apenas vê, mas também ouve. O videogame vai mais longe: o jogador, além de olhos e ouvidos, usa as mãos e, em alguns jogos, o corpo inteiro; não apenas assiste ao que acontece, vendo a ação do lado de fora da tela, mas interfere no rumo da ação, como se estivesse do lado de dentro. Integra-se ao jogo, correndo com os outros jogadores, interceptando a bola lançada pelo adversário, ou desviando o bote das rochas em disparada pelas corredeiras. Nos jogos de corpo inteiro, em que a animação da máquina é sincronizada com os movimentos do usuário, o jogo continua sendo uma simulação, mas o suor e o cansaço do jogador humano no fim do jogo são reais. O videogame, ao contrário de um filme, não avança sem esse esforço contínuo do jogador. Não é uma atividade puramente mental; envolve também o corpo em suas ações físicas (AARSETH, 1997). 


\subsection{Suporte eletrônico}

Todo videogame tem um suporte eletrônico. $O$ videogame surge de uma estrutura abstrata, especialmente formalizada para ser instanciada em suporte eletrônico, uma espécie de unidade de processamento central; é ali que os bilhões de bits combinam-se em sequências lógicas para adquirirem movimento, tomar decisões diante das açôes do usuário, avaliar suas jogadas, sugerir rumos ou gerar opções para desafiá-lo. $\mathrm{O}$ videogame, em sua dinâmica característica, não tem como instanciar-se numa folha de papel ou num tabuleiro. Por ser uma estrutura abstrata e invisível aos olhos, mesmo quando instanciada no circuito eletrônico da máquina, precisa de uma interface para chegar ao jogador. Entre os recursos que caracterizam essa mediação, estão a tela ou monitor, alto-falantes e inúmeros elementos gráficos que informam o andamento do jogo como cursores, botôes e barras de rolagem, além de dispositivos de entrada como teclado, controles, mouse, joysticks, pedais, volantes, etc. Esses recursos de mediação criam um ponto de junção não só entre o jogador e o próprio jogo instanciado na máquina mas também entre software e hardware, input e output, abrindo um portal por meio do qual a atividade do jogador acontece (WOLF; PERRON, p. 15).

O algoritmo, o suporte eletrônico e a atividade física do jogador apresentam níveis de dependência entre si que podem ser caracterizados da seguinte maneira: o algoritmo depende do suporte eletrônico para se instanciar; o suporte eletrônico, por sua vez, não só hospeda o algoritmo mas também viabiliza a interface com o jogador; o jogador, com sua atividade, é o que faz o videogame acontecer. Note-se que todos esses elementos já estavam presentes no "Tennis for Two", apresentado na feira de Nova York, em 1958. O problema, no entanto, é que o videogame evolui. A bolinha de cor verde que se movimentava na tela escura transforma-se num guerreiro, os cliques sonoros viram falas completas, avatares são introduzidos, a simples interatividade com a máquina isolada transforma-se numa interação em rede, e o resultado é que alguns videogames acabam sendo mais videogames do que outros, introduzindo elementos novos em sua definiçãa, como os conceitos de jogabilidade (VANUCCHI; PRADO, 2009), ludicidade, narratividade e ficção interativa (TAVINOR, 2008). Daí a proposta de que o videogame seja definido nos termos da Teoria dos Protótipos (LAKOFF, 1987), sem acreditar, no entanto, no "deslumbramento da taxonomia" (FOUCAULT, 1981, p. 5). 
Não há espaço aqui para se discutir em detalhes a Teoria dos Protótipos aplicada aos videogames, mas alguns pontos devem ser destacados. A primeira questão é que o algoritmo, o suporte eletrônico e a atividade do jogador são elementos necessários, mas não suficientes para definir um videogame. Um exercício interativo em que o aluno respondesse a perguntas feitas pelo computador com feedback automático tem um algoritmo, um suporte eletrônico e a atividade do aluno, mas não seria considerado um videogame pelo aficionado: falta-lhe o atributo da ludicidade; um videogame que diverte e vicia é mais videogame do que um que não cativa o usuário. A segunda questão é que a ludicidade, como também a jogabilidade e a interatividade, são variáveis contínuas, que se apresentam num gradiente de valores, e não variáveis categóricas, marcadas apenas por presença ou ausência. Todos os videogames terão jogabilidade e interatividade, por exemplo, mas em níveis que podem ser mais elevados ou menos elevados. Será a presença de índices mais elevados que caracterizará um videogame como mais prototípico. Já índices baixos de jogabilidade, interatividade e ludicidade colocariam a atividade numa zona de fronteira entre o videogame e outros eventos como a consulta a um mapa interativo na internet.

Uma última questão que precisa ser abordada na definição de videogame, ainda que rapidamente aqui, é se ele pode ou não ser considerado uma forma de arte (JENKINS, 2005). Há inúmeros argumentos, tanto contra como a favor. Entre os argumentos contrários está a ideia de que o videogame é incapaz de produzir a emoção estética das artes clássicas como a dança, a música, a pintura, a literatura ou mesmo o cinema: "os games podem ser divertidos e gratificantes em muitos aspectos, mas não podem transmitir a complexidade emocional que éa raiz da arte" (KROLL, 2000, online). Para Kroll, falta ao videogame o realismo do cinema, que não apenas simula o ser humano, mas grava-o em carne e osso: "a sensualidade de Lara Croft em Tomb Raider cai por terra diante do rosto de Sharon Stone" (KROLL, 2000, online).

O problema com o argumento de Kroll é mais ou menos óbvio: o texto foi escrito em 2000 e desde então o cinema e, principalmente, o videogame mudaram muito. $\mathrm{O}$ cinema deu realismo ao desenho animado, apresentando imagens bi- e tridimensionais com tal profusão de detalhes que muitas vezes não só se confunde com a realidade, mas a supera. Os próprios atores misturam-se com figuras animadas numa mesma cena, dão voz aos bonecos virtuais e, mais 
recentemente, por meio de uma técnica conhecida como motion capture, bailarinos têm sido usados para emprestar seus gestos às figuras desenhadas na tela, tornando os movimentos mais graciosos. A fusão de atores, dançarinos, bonecos e desenhos animados num único personagem, um ser fantástico, um animal ou um objeto, é capaz de reproduzir a alegria e a tristeza de um ser humano muito além da capacidade de expressão de um ator; a ponto de muitas vezes o simulado comover mais que o real.

$\mathrm{O}$ videogame evoluiu mais ainda, não só no realismo da imagem, na agilidade do movimento, mas principalmente na interação com o usuário. Todas as artes anteriores ao videogame tratam o sujeito como observador (seja espectador, leitor, seja ouvinte), em que pese algumas raras tentativas de permitir ao sujeito que interfira na obra, como em algumas peças de teatro; já o videogame trata $o$ sujeito não apenas como observador, mas como agente (LEFFA, 2011). Daí talvez a primeira dificuldade em estudá-lo. A outra estaria no tipo de evolução que caracteriza o videogame como obra permanentemente inacabada. Outras obras de artes, quando lançadas, são geralmente consideradas prontas e não são seguidas de sucessivas ediçôes, revisadas e ampliadas, como acontece com os videogames.

$\mathrm{O}$ videogame é ainda uma arte emergente. As artes clássicas têm séculos de tradição e já aprenderam a comover o espectador apenas pela imagem ou o leitor apenas pelas palavras impressas na folha do livro. O videogame é uma arte essencialmente híbrida e oferece mais do que imagem e texto, mais do que áudio e vídeo; oferece interatividade, apoiada pelos avatares, imagens que podemos criar a nossa semelhança ou a semelhança de deuses, mas próximo daquilo que gostaríamos de ser. A própria tecnologia do motion capture já se incorpora aos videogames, permitindo que o jogador interaja frente a frente com avatares, conduzindo ou sendo conduzido por eles, criando uma sincronia de movimentos mais realísticos para o mundo dos jogos. O videogame já evoluiu muito, a ponto de influenciar o próprio cinema, como podemos ver na ação frenética de Corra Lola, Corra ou na mistura de realidade com ilusão digital em Matrix (JENKINS, 2005), mas parece que ainda tem muito a evoluir.

\section{Videogame na aprendizagem de línguas}

Um levantamento dos estudos acadêmicos já realizados sobre o uso do videogame no ensino e aprendizagem de línguas leva a duas constataçóes 
imediatas. A primeira é que, embora o videogame já tenha sido bastante investigado sob diferentes perspectivas teóricas, incluindo a sociologia (BAINBRIDGE, 2010), a filosofia (CUDDY; NORDLINGER, 2009), os estudos identitários (CORNELIUSSEN; RETTBERG, 2008) e o letramento digital (GEE, 2003), estudos específicos sobre seu uso e papel na aprendizagem da segunda língua ou línguas estrangeiras (L2 doravante), embora tenham sido pensados desde a década de 1980 (ex.: BALTRA, 1984), são ainda muito escassos (VIDAL, 2011; De HAAN, 2011). A segunda constatação é que a longa tradição de CALL (Computer-Assisted-Language-Learning) tem gerado muitas atividades mediadas por computador, às vezes descritas como games educativos pela sua interatividade, uso de áudio e animaçōes, mas, com raras exceções, não passam de atividades tradicionais travestidas como jogo, na tentativa de ensinar e divertir ao mesmo tempo: "esses exercícios animados vestem-se como games, mas estão despidos de qualquer coisa que lembre um jogo" (OSTERWEIL; LE, 2010, p. 58). Diante dessa escassez de estudos teóricos e de trabalhos práticos, sentimos a necessidade, nesta seção, de não só olhar o que está sendo pesquisado e feito atualmente, ainda que brevemente, mas também de ir além e lançar um olhar para o futuro, tentando vislumbrar possíveis direções, com base no que se consegue observar, tanto na teoria como na prática.

Entre as pesquisas atuais, com ênfase específica no ensino e aprendizagem de L2, temos os trabalhos de Purushotma (2005), no MIT, De Haan (2008, 2011), na Universidade de Shizuoka, no Japão, e de Vidal (2011), com sua tese de doutorado, na Universidade Federal de Santa Catarina. Em termos de propostas práticas, temos o Projeto Xenos, do MIT, ainda em fase de desenvolvimento, mas com várias etapas já funcionais, e o software Quandary, desenvolvido na Universidade de Victoria, no Canadá. Destacamos aqui especificamente os trabalhos de Purushotma e o projeto Quandary.

A principal argumentação de Purushotma (2005) é de que os videogames podem tornar a aprendizagem da L2 interessante para o aluno. Ele próprio apresenta-se como um caso a ser estudado, considerando seu fracasso no estudo da língua estrangeira, devido ao tédio na execução dos exercícios que a aprendizagem da língua lhe impunha. Embora estivesse interessado em aprender alemão como L2 no ensino médio, foi reprovado, e já estava resignado a permanecer para o resto da vida um monolíngue em inglês, quando descobriu o potencial do videogame; não só aprendeu a língua como teve também o curso 
de sua vida mudado, na medida que se tornou um game designer no MIT, especializando-se no uso de videogames para a aprendizagem de línguas. Sua proposta é de que os videogames podem ser configurados para atender aos interesses do usuário, permitindo, por exemplo, a escolha da língua em que deseja jogar e tenha, assim, a possibilidade de aprender de forma lúdica. É dele também a elaboração dos princípios que devem nortear a produção de videogames para a aprendizagem de línguas (PURUSHOTMA; THORNE; WHEATLEY, 2009); neles, Purushotma e seus colegas tentam incorporar elementos da complexidade da narrativa, da ludicidade e da interação social ao ensino de línguas baseado em tarefas. A ideia é de que o cruzamento das mídias pode propiciar um ambiente mais estimulante e autêntico para a aprendizagem da língua, que é usada não como um fim em si mesma, mas como instrumento de lazer que acaba resultando em sua aquisição de modo incidental pelo aluno.

Quandary, por outro lado, é um sistema de autoria para a elaboração de games, permitindo, assim, que o professor monte seu próprio jogo ou use os que estão disponibilizados por outros professores na internet. De concepção simples, com base no princípio do labirinto, o sistema oferece ao autor da atividade uma estrutura aberta, possibilitando encaixar diferentes cenários, personagens e enredos, em inúmeras combinações. $\mathrm{O}$ jogo pressupõe uma missão, que deverá ser cumprida pelo usuário, desde o resgate de um prisioneiro de guerra, até o desafio de sobreviver num país estrangeiro com pouco conhecimento de sua língua e cultura. As possiblidades de uso da língua são inúmeras, seja um vídeo, uma fala, seja um texto escrito com mensagens que precisam ser compreendidas pelo aluno para que ele possa prosseguir na missão, tomando a decisão certa em cada encruzilhada do labirinto.

A proposta de Purushotma e o software Quandary não esgotam as possibilidades do uso de games para o ensino da L2, mas dão conta de duas questôes fundamentais: (1) usar o que já existe, fazendo adaptaçôes quando necessárias ou (2) criar, partindo do que ainda não existe. Em um ou outro caso, a visão que se tem de aprendizagem é a mesma, pelo menos em termos do conteúdo a ser trabalhado pelo aluno: a aprendizagem da língua é uma prática significativa que incorpora a apropriação do código, mas não está restrita a ele. Aprender uma L2 não é apenas aprender um repertório de frases; é aprender a encaixar as frases ao contexto, desde o corpo e seus movimentos aos rituais de interação nas tentativas de pertencimento a novas comunidades, quer sejam 
virtuais, quer sejam reais. Mais do que aprender a falar e a escrever, o aluno, com o game, tem a possibilidade de aprender a ser, convivendo com diferentes identidades e explorando seus próprios avatares.

Quando se pensa no uso de videogames para o ensino de línguas, está-se propondo em transformar o lazer, que é a finalidade do jogo, em um meio para um fim diferente, que é a aquisição da língua. Essa transformação de meio em fim tem algumas implicações que precisam ser consideradas. Em algumas correntes de aprendizagem de línguas (ex.: KRASHEN, 1989), sua aquisição tem sido vista como incidental, isto é, o aluno adquire a língua enquanto sua atenção está voltada para aspectos não essencialmente linguísticos. Seguindo essa linha de raciocínio, no caso dos videogames, o aluno jogaria com o objetivo único da diversão, mas, com a prática contínua do jogo, acabaria incidentalmente adquirindo a L2. Não é o que defendemos aqui. Entendemos que o objetivo de quem joga para aprender é diferente do objetivo de quem joga para se divertir. No caso do World of Warcraft, por exemplo, quem jogasse por diversão optaria pela versão traduzida do jogo; quem jogasse para aprender inglês escolheria a versão original. Ainda que seja possível usar o mesmo meio para atingir dois objetivos diferentes, situação em que se tenta unir o útil ao agradável, o objetivo específico de aprender a L2 é visto aqui como necessário: o aluno precisa ter o desejo de aprender.

\section{Conclusão}

Este trabalho propõe que o videogame pode ser usado como instrumento de mediação para a aprendizagem de línguas. Para isso, considerando que o videogame é muitas vezes mal visto por pais e professores, tivemos inicialmente a preocupação de mostrar que ele se constitui historicamente como uma prática social, tendo sua origem em um centro de pesquisa universitário e dali evoluído para as redes sociais, a ponto de ser considerado atualmente uma arte, como o cinema e a literatura, sem prejuízo do valor estético e enfrentando as mesmas questôes éticas. Mostramos que há vários tipos de games, não só com ênfase na ação, mas também no uso do raciocínio, da estratégia e da colaboração.

Vimos que, por ser uma prática social, o videogame propicia oportunidades de prática da língua em situaçôes simuladas e autênticas de uso. As simulaçóes podem ser vividas nas inúmeras possibilidades de interação criadas pelos games, em que o aluno participa não apenas como ouvinte ou leitor, mas 
como agente, entrando na história, construindo identidades, assumindo avatares, interferindo no enredo e mudando o curso da narrativa. No mundo dos games, a realidade interfere na virtualidade e permite ao sujeito interagir autenticamente com outros sujeitos. É de se supor que essas possibilidades de interaçōes virtuais e reais induzam o envolvimento maior do aluno.

O computador caracteriza-se por potencializar a ação do sujeito pelo recurso da agência, tanto no trabalho como no lazer. No trabalho, facilita inúmeras tarefas, preenchendo automaticamente os totais em uma planilha, buscando sinônimos para uma palavra, sugerindo correções, oferecendo traduções, entre tantas outras. No lazer, pode oferecer ao sujeito a possibilidade de viver em outros mundos, ajudando-o a construir outras identidades, distribuindo poderes, oferecendo avatares para com ele dançar, correr, lutar e até voar para outras galáxias.

$\mathrm{Na}$ área da educação, a questão da agência parece ser mais complexa. Se por um lado é fácil criar exercícios e atividades didáticas para os alunos, por outro, fica difícil garantir valor pedagógico para essas atividades, incluindo a capacidade de seduzir o aluno, como os games fazem com o usuário, a ponto, às vezes, de viciá-lo no jogo. A proposta deste trabalho é de que o uso de games para a aprendizagem de línguas, quer criados especificamente para esse fim, quer configurados a partir dos que já existem, pode ser uma ideia interessante.

Mesmo assim, por maior que seja a potencialidade de sedução do game, entendemos que nada elimina a necessidade do desejo. $\mathrm{O}$ aluno precisa desejar e ter como objetivo a aprendizagem da língua. Só assim, conseguirá transformar o objeto de lazer, que é o jogo, em um instrumento de mediação para chegar ao seu objetivo.

\section{Referências}

AARSETH, E. Ergodic Literature. Baltimore, Maryland: The John Hopkins University Press, 1997.

ASHER, R. Language and the power of puppets. In: DAVIS, J. F. (Org.). World language teacher education: transitions and challenges in the twenty-first century. Nova York: Information Age Publishing, 2010. p. 17-31.

BAINBRIDGE, W. S. The Warcraft Civilization: Social Science in a virtual world. Cambridge, MA: MIT Press, 2010. 
BALTRA, A. An EFL classroom in a mystery house. TESOL Newsletter, v. 18, n. 6, p. 15, 1984.

CHAMBERS, A.; BAX, S. Making CALL work: towards normalisation. System, v. 34, n. 4, p. 465-479, 2006.

CORACINI,M. J. R. F. Identidades múltiplas e sociedade do espetáculo: impacto das novas tecnologias de comunicação. In: CORACINI, M. J. R. F.; GRIGOlETTO, M.; MAGAlHÃES, I. (Org.). Práticas identitárias de língua e discurso. São Carlos: Claraluz, 2006. p. 133-156.

CORNELIUSSEN, H.; RETTBERG, J. W. (Org.). Digital Culture, Play, and Identity: a World of Warcraft. Cambridge, MA: MIT Press, 2008.

CUDDY, L.; NORDLINGER, J. (Org.). World of Warcraft and Philosophy: wrath of the Philosopher King. Chicago: Open Court, 2009.

CYRILLO, F. N. Videogame é utilizado em reabilitação de pacientes. Scientific American Brasil. Disponível em: <http://www2.uol.com.br/sciam/noticias/ videogame_e_utilizado_em_reabilitacao_de_pacientes.html>. Acesso em: $9 \mathrm{fev}$. 2011.

De HAAN, J. W. Video games and second language acquisition: the effect of interactivity with a rhythm video game on second language vocabulary recall, cognitive load, and telepresence. Unpublished doctoral dissertation. New York University, 2008.

De HAAN, J. W. Teaching and learning English through digital game projects. Digital Culture \& Education, v. 3, n. 1, p. 03-29, abr., 2011. Disponível em: <http:/ /www.digitalcultureandeducation.com/cms/wpcontent/uploads/2011/04/ dce1046_deHaan_2011.pdf>. Acesso em: 9 fev. 2011.

FOUCAULT, M. As palavras e as coisas: uma arqueologia das ciências humanas. Trad. Salma Tannus Muchail. São Paulo: Martins Fontes, 1981.

GEE, J. P. What Videogames have to teach us about learning and literacy. Madison, 2003.

GETTLER, J. The first video game? Before Pong, there was Tennins for Two.

Brookhaven History: 2008. Disponível em: <http://www.bnl.gov/bnlweb/history/ higinbotham.asp >. Acesso em: 9 fev. 2012.

HIGINBOTHAM, W. Notes. 1983. Disponível em: <http://www.bnl.gov/bnlweb/ history/linkable_files/HiginNotes.pdf>. Acesso em: 9 fev. 2011.

JBRUNO. Imagens da época de ouro dos fliperamas. Outer Space. Disponível em: $<$ http://forum.outerspace.terra.com.br/showthread.php?t=104228>. Acesso em: 27 set. 2011. 
JENKINS, H. Games, the new lively art. In: GOLDSTEIN, J.; RAESSENS, J. (Org.). Handbook of computer games studies. Cambrige: MIT Press, 2005. p. 175-192.

KNOBEL, M.; LANKSHEAR, C. A new literacies sampler. New York, Peter Lang Publishing, Inc. 2007.

KRASHEN, S. We acquire vocabulary and spelling by reading: additional evidence for the input hypothesis. The Modern Language Journal, v. 73, p. 440-464, 1989.

KROLL, J. Emotional engines? I don't think so. Newsweek, 27 fev. 2000. Disponível em: <http://www.thedailybeast.com/newsweek/2000/03/05/emotion-engine-i-dont-think-so.html>. Acesso em: 9 fev. 2011.

LAKOFF, G. Women, fire and dangerous things: what categories reveal about the mind. Chicago: The University of Chicago Press, 1987.

LEFFA, V. J. Call as action. In: MARRIOTT, R. C. V; TORRES, P. L. (Org.). E-learning methodologies for language acquisition. Hershey PA: IGI Global, 2009. p. 39-52.

LEFFA, V. J. Interação, mediação e agência na aprendizagem de línguas. In: BARCELOS, A. M. F. (Org.). Linguistica Aplicada: reflexōes sobre ensino e aprendizagem de língua materna e língua estrangeira. Campinas, SP: Pontes Editores, 2011. p. 275-295.

MANJASTER. Fliperamas: o fim de uma era. UOL Jogos. 2008. Disponível em: $<$ http://forum.jogos.uol.com.br/fliperamas-o-fim-de-uma-era-nostalgia-parapoucos_t_46232?page $=2>$. Acesso em: 27 set. 2011

NOVA ESCOLA. Um guia sobre o uso de tecnologias em sala de aula. Disponível em: <http://revistaescola.abril.uol.com.br/avulsas/223_materiacapa_abre.shtml>. Acesso em: 23 ago. 2011. Nova Escola. Edição 223, jun. 2009.

OSTERWEIL, S.; LE, L. X. Learning and change: a view from MIT's Education Arcade. The International Journal Cognitive Technology. v. 14, n. 2, p. 58-65, 2010.

PAIVA, V.L.M.O. O uso da tecnologia no ensino de linguas estrangeiras: breve retrospectiva histórica. 2008. Disponível em: <http://www.veramenezes.com/ techist.pdf>. Acesso em: 9 fev. 2012.

PRADO, C. Lan houses não são "antros de perdição". 2011. Disponível em: <http:/ /www.abcid.org.br/lan-houses-nao-sao-\%E2\% $80 \% 9$ Cantros-deperdicao\%E2\%80\%9D>. Acesso em: 9 fev. 2012.

PURUSHOTMA, R. Commentary: you're not studying, you're just... Language Learning \& Technology v. 9, n. 1, p. 80-96, jan. 2005. Disponível em: <http:// llt.msu.edu/vol9num1/purushotma/default.html>. Acesso em: 2 mar. 2012. 
PURUSHOTMA, R.; THORNE, S. L.; WHEATLEY, J. 10 key principles for designing video games for foreign language learning, 2009. Open language \& learning games project, MIT. Disponível em: <http://knol.google.com/k/10-key-principlesfordesigning-video-games-for-foreign-language-learning\#>. Acesso em: 2 mar. 2012.

RODRIGUES, J. Videogame Wii põe diversão na fisioterapia. Disponível em: $<$ http://veja.abril.com.br/noticia/saude/videogame-wii-poe-diversao-fisioterapia>. Acesso em: 23 ago. 2011. Veja, 29 jun. 2009.

SNYDER, I. Shuffling towards the future: the enduring dominance of book culture in literacy education. In Baynham, M \& Prinsloo, M. (Ed.). The Future of Literacy Studies. London: Palgrave Macmillan, 2009. p.141-159.

TAVINOR, G. Definition of videogames. Canterbury, New Zealand: Lincoln University, 2008. Disponível em: <http://www.contempaesthetics.org/newvolume/ pages/article.php?articleID=492>. Acesso em: 9 fev. 2011.

VAISBERG, T. M. J. A. Marionetes em consultas terapêuticas: a teoria dos campos na fundamentação de enquadres transicionais. In: BARONE, L. M. C. (Org.). O Psicanalista: hoje e amanhã. O II encontro psicanalítico da teoria dos campos. São Paulo: Casa do Psicólogo, 2002. p. 203-220.

VANNUCCHI, H.; PRADO, G. Discutindo o conceito de gameplay. Revista Texto Digital, v. 5, n. 2, online, 2009. Disponível em: <http://www.textodigital.ufsc.br/ num09/heliagilbertto.htm>. Acesso em: 9 fev. 2011.

VENTICINQUE, D. A guerra chegou ao Brasil. Época, p. 115-119, 2011.

VIDAL, C. D. Multimodalidade e traduções funcionais para investigar a aquisição de segunda língua em gamers. 2011. Tese (Doutorado) - Programa de Pós-Graduação em Estudos da Tradução, Universidade Federal de Santa Catarina, Florianópolis, 2011.

WOLF, M. J. P.; PERRON, B. Introduction. In: (Org.). The videogame theory reader. New York: Routledge, 2003. p. 1-24. 